\title{
Establishing a Benchmark for the Deductive Reasoning Abilities of United Arab Emirates University Business Students
}

\author{
John McLellan
}

UAE University

\section{Introduction}

An effective measuring tool is a necessary requirement for the improvement of deductive reasoning abilities of students. The purpose of this research is to determine the efficacy of the Cornell Conditional Reasoning Test Form $X$, in measuring the deductive reasoning abilities of students living in a culture different than the culture for which the test was designed and for whom the English language is not their mother tongue. There have been many studies on measuring the critical thinking abilities of students in North America (Ennis and Paulus, 1965; Nolan and Brandon 1984; Ennis and Weir, 1985; Facione, 1991; Brandon 1997), however there no published studies measuring the deductive reasoning abilities of students in the Middle East. This study was conducted with business students enrolled in the College of Business and Economics at the United Arab Emirates University (UAEU).

The test used in this study was the Critical Thinking Readiness in Grades 1-12 (Phase 1: Deductive Reasoning in Adolescence). The test was originally developed as part of the Illinois Critical Thinking Project, Department of Educational Policy Studies. The Project's purpose was to determine if students in New York State aged 10-17 years could be taught critical thinking skills. The principal investigators in that research project stated that their objectives "are to contribute to knowledge about what critical thinking is and to knowledge about when it can be taught" (Ennis et al 1964). They then developed and refined a list of abilities which characterized the critical thinker.

"A critical thinker is characterized by proficiency in judging whether:

1. A statement follows from the premise.

2. Something is an assumption.

3. An observation statement is reliable.

4. A simple generalization is warranted.

5. A hypothesis is warranted.

6. A theory is warranted.

7. An argument depends on an ambiguity.

8. A statement is over vague or over specific.

9. An alleged authority is reliable.

Deductive logic, the subject of the current study, is a central part of critical thinking, as analyzed above" (Ennis et al 1964). 
The project was conducted with over five hundred students in upper New York State. The success of the project led to the development of the Cornell Conditional Reasoning Test Form X and Form Y currently available for purchase over the internet. The principle author Dr. Robert Ennis has allowed the test to be used in the UAE and has provided the marking key to evaluate the results.

This test was also used in Jamaica from 1984 to 1992 to test senior high school students as well as forming part of the entrance examination requirements for students entering the Department of Education Bachelors Degree program (Nolan and Brandon 1984). The original Cornell test was designed using what they called concrete familiar statements, in which the content mentioned was "concrete articles and qualities with which the subject has been associated" (Ennis et al 1964). The Jamaican project modified the exam to create concrete familiar content for their subjects. For this current research project the original test was not modified in any aspect.

Critical thinking tests have been used extensively in North America for over the past forty years to measure students' ability. These tests are in English and the test questions require familiarity with American terminology. To date, no tests have been developed for students in the Middle East. This research project is an attempt to establish whether or not the Cornell Conditional-Reasoning Test, Form $X$ as it was originally designed in 1965, will be effective in measuring the deductive reasoning abilities of CBE students and to establish a benchmark against which future CBE students' logical abilities can be measured.

Conditional reasoning is based on an "If $P$ then $Q$ " construct that posits $Q$ to be true if $P$ is true. However, if $P$ is false, $Q$ can logically be true or false. In the statement "If $P$ then $Q$ ", $P$ is the antecedent and $Q$ is the consequent. Situations are presented that can affirm or deny either the antecedent or consequent and thereby create statements that could be logically true or logically false. Seventy-two of these situations were presented to three hundred and sixty-one business students at the College of Business and Economics (CBE).

This report begins with a review of the literature on studies involving critical thinking skills of students in general and the deductive reasoning studies in particular. The next section outlines the unique educational experience of business students at UAEU, how that experience is different from students in other countries and the challenges that these students face in an international business environment. Then, this report will examine the research instrument used in this study, the purpose for which it was designed and the history of its use. Following that section is the research methodology on how the survey of three hundred and sixty one business students was conducted; then, the research hypotheses are developed. The penultimate section analyses the data and statistical results on the test of each hypothesis. The final section concludes the study and suggests continued research possibilities.

\section{Literature review}

There is much research that has recently been conducted on critical thinking; the meaning of critical thinking; the use of critical thinking tests and the transferability of critical thinking skills. There have also been a number of academics and business practitioners who are calling for the need for college students to be able to think logically and to critically evaluate situations. "The skills I find hardest to get into people are analytical thought processes and critical thinking" said one management accountant at Caterpillar Corporation in the United States (Siegel, 2000).

Ennis and Weir (1985) define critical thinking as reflective and reasonable thinking that is focused on deciding what to believe or do. They believe that this concept of critical thinking is "a much clearer

McLellan, J. (2009). Establishing a benchmark for the deductive reasoning abilities of United Arab Emirates University Business students. Learning and teaching in higher education: Gulf perspectives 6(2). 
concept than the currently popular higher order thinking skills" and the top three levels of Bloom's taxonomy (analysis, synthesis and evaluation). A national panel of experts who participated in a two year Delphi research project aimed at achieving a consensus of what would constitute "critical thinking abilities in college freshman and sophomores", (first and second year college students). The consensus states in part:

We understand critical thinking to be purposeful, self-regulatory judgment which results in interpretation, analysis, evaluation and inference, as well as explanation of the evidential, conceptual, methodological, criteriological,(sec)or contextual consideration upon which judgment is based. (Facione, 1991).

The operational difficulty of such broad and general definitions of critical thinking skills is expressed by Broadbear in his article on designing lessons to promote critical thinking skills when he states that a major barrier educators face in infusing critical thinking throughout teaching and learning at the higher educational level is " the difficulty many educators have in translating the concept of critical thinking into pragmatic, pedagogical approaches"(2003).

Stylianides and Stylianides' (2008) study focuses on one major component of the set of skills collectively known as critical thinking skills, namely deductive reasoning and examines two psychological theories to help improve the deductive reasoning skills of students: the mental models theory (Johnson-Laird, 1983; Johnson-Laird \& Byrne, 1991) and the pragmatic reasoning schema theory (Cheng \& Holyoak, 1985). The mental model theory argues that "people make decisions by building models and searching for counterexamples" (Johnson-Laird and Byrne, 1991) whereas pragmatic reasoning schemas are "clusters of rules that are highly generalized and abstracted but nonetheless defined with respect to classes of goals and types of relationships" (Cheng et al, 1986). They conclude that the two cognitive psychological theories of deductive reasoning offer useful insights into ways to foster student's abilities for deductive reasoning. Both theories are placed in the context of a North American culture and Norris (1985) stated that critical thinking skills are sensitive to context - "students' background knowledge and assumptions can strongly affect their ability to make correct inferences." McPeck (1981) makes a similar point about deductive reasoning when he states that people reason better deductively when dealing with thematic context that relate to their personal experience. Hence, it would be expected that students in the Middle East would score lower on a deductive reasoning test designed for students in the West.

There have been a number of tests that have been developed in the past forty years to measure critical thinking abilities. Ennis (1999) offers a list of such tests in use in North America. The list is divided into tests that are "multi-aspect" critical thinking tests and tests that are "specific - aspect" (i.e. deductive reasoning tests). All tests are in English and use concrete examples that would be familiar to a North American student.

The test used in this study of students in the UAE was a test designed to measure the deductive reasoning abilities of students in North America. The educational system in the UAE is considerably different than the educational system in the United States and is described in the next section.

\section{Educational system in the UAE}

The UAE consists of seven Emirates. Situated on the Arabian Gulf east of Saudi Arabia, the country has a long history of local tribal lifestyle. The UAE is ruled by appointed families established at the time of nation's formation and there are no political parties.

McLellan, J. (2009). Establishing a benchmark for the deductive reasoning abilities of United Arab Emirates University Business students. Learning and teaching in higher education: Gulf perspectives 6(2). 
The educational system in the UAE is relatively new as it was only in the 1950's that the system was developed with separate schools for boys and girls. Primary education is today compulsory in the UAE. The curriculum is heavily influenced by curricula in the UK, Canada, USA and India (Bradshaw et al 2004).

The United Arab Emirates University (UAEU) was established in 1977, six years after the creation of the nation. The university is in Al Ain, a city of 600,000 situated at the eastern edge of the Abu Dhabi Emirate. It was established by the ruler at that time to provide a university education free of charge for all UAE nationals.

The students come from all the emirates, with about $60 \%$ being from the Al Ain region. Resident students are bused home and back every weekend. The university has numerous campuses, most of which are segregated by gender. Classes are not of mixed gender. Female students outnumber male students two to one. Most students have completed their secondary education in local Arabic-medium schools and, upon entering university, take a foundation program in which they study English, Arabic, Math and IT, both remedially and developmentally. As they progress through the program and attain a certain level on the Academics IELTS (International English Language Testing Service), they articulate to their colleges and complete their university studies. Most university programs are now taught in English. At the College of Business and Economics, all communication between faculty and students has to be conducted in English.

Undergraduate students at UAEU are, for the most part, between 18 and 23 years old and have been going to school most of their lives. Ninety-five percent of students are UAE nationals; the remaining five percent are mostly from other Arab countries.

Education at UAEU is free for those who show some ability to study in English; therefore, most students do not have work experience outside of university. Upon graduation, many students seek employment with the various government departments or agencies. The official language of government is Arabic, but English is often required.

The educational system in the UAE has been criticized for focusing exclusively on learning by rote memory. The memorization ability of national students is phenomenal. At the university level, courses are being designed to improve the critical thinking skills of the students. Improvement in any process requires effective measurement tools. This deductive reasoning research study is an attempt to establish a measurement of the current reasoning abilities of students. The following section describes the development and past use of the test.

\section{Research instrument}

The deductive reasoning test used in this study was the Cornell Conditional-Reasoning Test Form $\mathrm{X}$, published by the Illinois Critical Thinking Project, Department of Educational Policy Studies. That project was designed to measure the conditional reasoning ability of students in the state of New York aged 1017 and to determine if students receiving instruction in logical thinking would score higher than students not receiving instruction (Ennis et al 1964).

The authors stated that the test questions were developed using language that a ten year - student would understand and with which a seventeen year old would not be offended. The reliability and validity of the test was established by the authors and the test was deployed in 1965 in Upper State New York (Ennis \& Paulus 1965).

McLellan, J. (2009). Establishing a benchmark for the deductive reasoning abilities of United Arab Emirates University Business students. Learning and teaching in higher education: Gulf perspectives 6(2). 
This test was also used in Jamaica (Nolan and Brandon 1984), in an investigation into competence in the principles of conditional reasoning among students in a comprehensive school in Hanover. In addition, it was used with teacher trainees in St. Lucia from 1985-1992 as a part of an entry examination for applicants to the Faculty of Education at the University of West Indies.

The Cornell Conditional-Reasoning Test Form $X$ was constructed to determine the degree to which students would master the principles of logic as listed below:

1. Given an if-then sentence, the affirmation of the if part implies the affirmation of the then part. (If $p$, then q. p. Therefore $q$. Valid)

2. Given an if-then sentence, the denial of the if-part does not by itself (as a result of its being an ifpart) imply the denial of the then-part. (If $p$, then $q$. Not $p$. Therefore not $q$. Invalid)

3. Given an if-then sentence, the affirmation of the then-part does not by itself (as a result of its being a then-part) imply the affirmation of the if-part. (If $p$, then $q$. $q$. Therefore $p$. Invalid)

4. Given an if-then sentence, the denial of the then-part implies the denial of the if-part. (If $p$, then $q$. Not $q$. Therefore not $p$. Valid).

5. The if-then relationship is transitive. (If $p$, then $q$. If $q$, then $r$. Therefore, if $p$, then $r$. Valid)

6 An if-then sentence implies its contra positive. (If $p$, then $q$. Therefore, if not $q$, then not $p$. Valid)

7. The if-then relation is non-symmetric. (If $p$, then $q$. Therefore, if $q$, then $p$. Invalid).

8. Given an only-if sentence, the denial of the only-if part implies the denial of the major part. ( $p$ only if $q$. Not $q$. Therefore not $p$. Valid)

9. Given an only-if sentence, the affirmation of the major part implies the affirmation of the only-if part. ( $p$ only if q. $p$. Therefore $q$. Valid)

10. The denial or affirmation of one part of an if-and-only-if statement implies respectively the denial or affirmation of the other part. ( $p$, if and only if, $q$. Not $p$. Therefore not $q$. Valid)

11. Given an only-if sentence, the affirmation of the only-if part does not by itself (as a result of its being an only-if part) imply the affirmation of the major part. ( $p$ only if $q$. $q$. Therefore $p$. Invalid)

12. Given an only-if sentence, the denial of the major part does not by itself (as a result of its being the major part) imply the denial of the only-if part. ( $p$ only if $q$. Not $p$. Therefore not $q$. Invalid)

The test contains 72 statements covering the 12 principles or combinations of principles or item groups. There are six statements assigned to each principle or combination of principles. Each set of such items is referred to as an "item group"; therefore, there are twelve item groups in the test. The six statements within any one group are scattered throughout the test.

The format of the questions asks the subject to suppose a certain premise or premises and then, based on that supposition, to decide whether a further thing would be true. This further thing is called the proposed statement. There are three possible answers: "yes", "no" or "maybe." "Yes" indicates that the proposed statement follows necessarily. "No" signifies that the proposed statement contradicts the premise or premises and "maybe" means that the proposed statement neither follows necessarily nor contradicts. An example of each type of question is presented to the subject at the beginning of the test (see Appendix).

McLellan, J. (2009). Establishing a benchmark for the deductive reasoning abilities of United Arab Emirates University Business students. Learning and teaching in higher education: Gulf perspectives 6(2). 
Operational definitions of mastery of a principle were tied to the item groups. Students getting five or six of the six statements correct were deemed to have attained mastery of that principle; students getting at least 4 correct were judged to have probably mastered the principle and scores of three or less indicated failure to master the principle (Ennis and Paulus 1965). The manner in which the survey was carried out is presented next.

\section{Research methodology}

A pilot study was conducted with six female students. The students were in their final year of the accounting program at UAEU. They were instructed to record the time taken to complete the test and to indicate any English words that they had difficulty with as well as any terminology or phrases that were unfamiliar to them.

The average time taken to complete the test was fifty three minutes. The students reported a few difficulties with some of the wording but able to cope after looking the word up in a dictionary. One stated she had difficulty with the phrase "rides his bike", possibly because the word bike would not have appeared in a dictionary. Another stated she had trouble with question 52 concerning the words "pennant" and "homer". "Jumping rope" and "chalk" were also words unfamiliar to one student. One student reported that she did not understand fully four of the questions and therefore did not answer those questions. Other than that, the test they were able to complete the test. As a result of the pilot study, a decision was made not to make any changes to the test before administering it to other students. The students would be allowed to use the English/Arabic translator function on their laptops, however.

In the fall semester of 2007, the Cornell Conditional-Reasoning Test, Form X was administered to seventy-two female and twenty-six male accounting students in the Cost and Managerial Accounting course at UAEU. The instructions for the test were given exactly as the authors of the test had outlined and no attempt was made to explain any of the terminology the student may encounter. This process was repeated in the spring semester, this time with students in the Fundamentals of Managerial Accounting course (44 male and 32 female).

During the summer of 2008, an electronic version of the test was created and uploaded to a program called Surveymonkey. This software program allowed the students to complete the survey online and the results could then be downloaded to an Excel spreadsheet, thus eliminating the data entry portion of the research project.

In the fall of 2008, the test was administered to ninety-six students CBE students in the introductory managerial accounting course and one hundred and four in the advanced managerial accounting course ( Cost Accounting 351). The answers were combined with the results of the previous two semesters and this research project then is a report on the deductive reasoning ability of three hundred and sixty-one business students in the College of Business and Economics at UAEU.

The survey, in addition to the test questions, asked demographical questions such as the student's current GPA score, their current age, the number of course credit hours completed to date and whether the secondary school they attended was Arabic or English. All students were graduates of an Arabic secondary school. The demographic information on the students is presented in the next section.

McLellan, J. (2009). Establishing a benchmark for the deductive reasoning abilities of United Arab Emirates University Business students. Learning and teaching in higher education: Gulf perspectives 6(2). 


\section{Demographics}

There were three hundred and sixty- one students who took the test. Two hundred and forty -two were females and one hundred and nineteen were males. The majority of students were under the age of twenty two, with the largest age group being 21 years old (88) and the second largest group was 20 years old (61). Only about one third of the students participating in this study had a GPA score greater than 3 and more than half of the students were in the second part of their degree program (Table 1).

Table 1: Demographic data.

\begin{tabular}{|c|c|c|c|c|c|c|c|c|}
\hline & \multirow{2}{*}{\multicolumn{2}{|c|}{$\begin{array}{l}\text { Gender } \\
\text { Males } \\
\text { Females }\end{array}$}} & \multicolumn{2}{|c|}{$\underline{\text { Age }}$} & \multicolumn{2}{|c|}{$\underline{\mathrm{GPA}}$} & \multicolumn{2}{|c|}{ Credit Hours } \\
\hline & & & $\begin{array}{l}18-2 \\
25\end{array}$ & $22-$ & $\begin{array}{l}2-2.9 \\
3.99\end{array}$ & 3- & $\begin{array}{l}\leq 68 \\
132\end{array}$ & $69-$ \\
\hline STUDENTS & 119 & 242 & 229 & 56 & 226 & 127 & 150 & 197 \\
\hline
\end{tabular}

Four hypotheses were developed based on the demographic data.

\section{Research Hypotheses}

A hundred and sixteen male students and two hundred and forty-five female business students at the UAEU took the Cornell Conditional-Reasoning Test Form X. The results of the study conducted in 1965 in the United States with students whose first language was English indicated a slight difference in results favouring the females (Ennis and Paulus 1965). English was also the first language of the grade eleven students at the Rusea's Comprehensive Schools in Lucea, Jamaica. The same result was obtained by Nolan; that is, there was a slight difference but not a significant difference in scores between males and females (Nolan and Brandon 1984). In his study of the results of teacher trainees in St. Lucia, Brandon (1989) concluded that " the males we have tested do not perform any differently from females." Hence:

\section{Hypothesis 1}

There will be no significant difference in the results between the female and male students.

In the same study, Brandon also concluded that a more significant difference in performance on this test would be due to age. He and Nolan, in their study of high school students in Jamaica (Nolan and Brandon 1984) as well as Ennis in his study in the US (Ennis and Paulus 1965) have shown that there is significant improvement in scores of students in the lower grades to those in the upper grades. The students in this study range in age from eighteen to twenty-five with a median age of 21 . One would expect that older students would do better than younger students based on two facts: older students have had more exposure to the English language and older students are more mature and experienced. Therefore:

\section{Hypothesis 2}

There will be a significant difference in the results due to age. Older students will score higher than younger students.

Participants were also asked to report their GPA scores prior to the current semester. Norris (1985) states that students achieving the highest scores on critical thinking tests were enrolled in MBA and medical programs. Students who are high achievers will likely approach this conditional reasoning test more earnestly and will therefore put forth a greater effort and achieve better results. Therefore:

\section{Hypothesis 3}

McLellan, J. (2009). Establishing a benchmark for the deductive reasoning abilities of United Arab Emirates University Business students. Learning and teaching in higher education: Gulf perspectives 6(2). 
There will be a significant difference in the results between students with a GPA of three or greater and students with a GPA of less than three.

Some of the students were in the second year of the business degree program, some were in their third or fourth. Presumably, the more education a person has, the higher he or she will score on this test. Therefore:

\section{Hypothesis 4}

There will be a significant difference in the results between students who have completed more than sixty-eight credit hours and those who have less than sixty-eight before the current semester.

With these hypotheses stated, the results of the Cornell Conditional Reasoning Test are presented in the next section.

\section{Research results}

\section{Marking Scheme}

The marking key provided by the author of the test was applied to the answers. There was a scoring penalty for guessing wrong. Consistent with the manner in which the test has been scored in the past, the results were compiled as follows: $R-(W / 2)+29$. That is, the number of questions answered incorrectly (not counting questions not attempted) was divided by two and subtracted from the number of the seventy-two questions answered correctly. To the resulting number, 29 was added to give an overall score out of ninety-nine. In addition, each of the conditional logic item groups (1 through 12 ) was scored to determine the mean as well as the percentage of students who have mastered that particular principle - that is, who achieved five or six out of six correct - and those students who were borderline in achieving mastery by answering four out of six correct. Results are analysed next.

\section{Results and Comparison to the USA and Jamaican Study}

The overall mean score and standard deviation for the UAEU participants on the Cornell Conditional Reasoning test Form $X$ was 45.93 and 11.92, respectively. The mean score of the seventy-eight, seventeen year-old students in the USA was 56.6 with a standard deviation of 14.0. The result in the West Indies was a mean of 47.3 and 10.22 .

Table 2 presents a comparison of the degree of mastery on each item group in the test by the threehundred and sixty-one UAEU students, the vast majority aged 18-21; the seventy-eight, seventeen yearold students USA students and the eighty, seventeen year- old Jamaican students. A note concerning the USA students- in that study, one third of the students (26) received training in deductive reasoning. Therefore, the percentages presented in the USA study contain the results of the students trained in logic.

Table 2: Degree of mastery of deductive reasoning principles.

\begin{tabular}{|c|c|c|c|c|c|}
\hline $\begin{array}{l}00 \\
0 \\
\frac{0}{0} \\
\varepsilon \\
\mathbb{E} \\
\pm\end{array}$ & 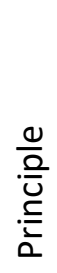 & Valid \& Invalid Statements & $\begin{array}{l}\text { UAEU } \\
\text { Mastered } \\
\text { Borderline } \\
5 \text { or } 6 \\
\quad 361 \\
\text { students }\end{array}$ & $\begin{array}{l}\text { USA } \\
\text { Mastered } \\
\text { Borderline } \\
5 \text { or } 6=4 \\
78 \\
\text { students }\end{array}$ & $\begin{array}{l}\text { Jamaica } \\
\text { Mastered } \\
\text { Borderline } \\
5 \text { or } 6 \quad=4 \\
\quad 80 \text { students }\end{array}$ \\
\hline
\end{tabular}

McLellan, J. (2009). Establishing a benchmark for the deductive reasoning abilities of United Arab Emirates University Business students. Learning and teaching in higher education: Gulf perspectives 6(2). 


\begin{tabular}{|c|c|c|c|c|c|c|c|c|}
\hline 1 & 1 & $\begin{array}{l}\text { If } p \text { then } q . P . \text { Therefore } q \text {. } \\
\text { (Valid) }\end{array}$ & $44 \%$ & $19 \%$ & $62 \%$ & $16 \%$ & $34 \%$ & $34 \%$ \\
\hline 2 & 2 & $\begin{array}{l}\text { If } p \text { then } q . \text { Not } P \text {. Therefore } \\
\text { not } q . \text { (Invalid) }\end{array}$ & $2 \%$ & $8 \%$ & $12 \%$ & $15 \%$ & $6 \%$ & $18 \%$ \\
\hline 3 & 3 & $\begin{array}{l}\text { If } p \text { then } q . Q . \text { Therefore } p \text {. } \\
\text { (Invalid) }\end{array}$ & $4 \%$ & $8 \%$ & $3 \%$ & $13 \%$ & $7 \%$ & $16 \%$ \\
\hline 4 & 4 & $\begin{array}{l}\text { If } p \text { then } q . \text { Not } Q . \text { Therefore } \\
\text { not } p \text {. (Valid) }\end{array}$ & $15 \%$ & $21 \%$ & $35 \%$ & $25 \%$ & $27 \%$ & $21 \%$ \\
\hline 5 & 5 & $\begin{array}{l}\text { If } p \text { then } q . \text { If } q \text { then } r \text {. } \\
\text { Therefore if } p \text { then } r \text {. (Valid) }\end{array}$ & $41 \%$ & $21 \%$ & $58 \%$ & $30 \%$ & $33 \%$ & $22 \%$ \\
\hline 6 & 6 & $\begin{array}{l}\text { If } p \text {, then } q . \text { Therefore if not } \\
q \text {, then not } p . \text { (Valid) }\end{array}$ & $21 \%$ & $19 \%$ & $33 \%$ & $20 \%$ & $27 \%$ & $28 \%$ \\
\hline 7 & 7 & $\begin{array}{l}\text { If } p \text {, then } q \text {. Therefore } q \text {, } \\
\text { then } p \text {. (Invalid) }\end{array}$ & $9 \%$ & $8 \%$ & $19 \%$ & $13 \%$ & $6 \%$ & $14 \%$ \\
\hline 8 & 8 & $\begin{array}{l}P \text { only if } q . \text { Not } q . \text { Therefore } \\
\text { not } p \text {. (Valid) }\end{array}$ & $57 \%$ & $18 \%$ & $79 \%$ & $12 \%$ & $62 \%$ & $21 \%$ \\
\hline 9 & 9 & $\begin{array}{l}P \text { only if } q . P . \text { Therefore } q . \\
\text { (Valid) }\end{array}$ & $57 \%$ & $23 \%$ & $81 \%$ & $14 \%$ & $42 \%$ & $29 \%$ \\
\hline 10 & $1 \& 5$ & $\begin{array}{l}P \text { if and only if } q . \text { Not } p . \\
\text { Therefore not } q \text {. (Valid) }\end{array}$ & $35 \%$ & $19 \%$ & $58 \%$ & $19 \%$ & $38 \%$ & $13 \%$ \\
\hline 11 & 10 & $\begin{array}{l}P \text { only if } q . Q . \text { Therefore } p \text {. } \\
\text { (Invalid) }\end{array}$ & $30 \%$ & $24 \%$ & $40 \%$ & $26 \%$ & $27 \%$ & $29 \%$ \\
\hline 12 & $\begin{array}{l}1 \& 1 \\
1\end{array}$ & $\begin{array}{l}P \text { only if } q . \text { Not } p \text {. Therefore } \\
\text { not } q . \text { (Invalid) }\end{array}$ & $3 \%$ & $5 \%$ & $0 \%$ & $5 \%$ & $9 \%$ & $6 \%$ \\
\hline
\end{tabular}

Combining the percentages of mastered and borderline on each item group for each of the three studies, it is apparent that the USA students achieved a higher percentage than both the Jamaican students and the UAE students on all of the item groups. For example in item group 1, the combined percentage for UAEU was $63 \%$, the USA $88 \%$ and Jamaica $68 \%$. The results of the UAEU students compared with the students in Jamaica were that for most of the item groups the Jamaican students scored higher but on two of the groups - group 5 (62\% vs. 55\%) and group 9 ( $80 \%$ vs. $71 \%)$, the UAEU students demonstrated greater mastery.

As a further comparison of results, the mean score on each of the twelve item groups is presented in Table 3 for students in the UAEU compared to the USA results Nolan's (1984) study does not present the mean scores for each item group, only the percentage of mastery as in Table 2. The percentage difference between the results is also presented.

Table 3: Item groups' mean scores.

\begin{tabular}{|l|l|l|l|l|l|l|l|l|l|l|l|l|}
\hline $\begin{array}{l}\text { Item } \\
\text { Groups }\end{array}$ & 1 & 2 & 3 & 4 & 5 & 6 & 7 & 8 & 9 & 10 & 11 & 12 \\
\hline UAEU & 4.05 & 1.68 & 1.72 & 3.08 & 3.85 & 3.06 & 1.74 & 4.41 & 4.45 & 3.54 & 3.50 & 1.29 \\
\hline USA & 4.7 & 2.2 & 2 & 3.9 & 4.5 & 3.6 & 2.6 & 5.2 & 5.2 & 4.5 & 3.9 & 1.3 \\
\hline $\begin{array}{l}\text { Percentage } \\
\text { Differences }\end{array}$ & $16 \%$ & $30 \%$ & $16 \%$ & $27 \%$ & $17 \%$ & $18 \%$ & $49 \%$ & $18 \%$ & $17 \%$ & $27 \%$ & $11 \%$ & $.8 \%$ \\
\hline
\end{tabular}

McLellan, J. (2009). Establishing a benchmark for the deductive reasoning abilities of United Arab Emirates University Business students. Learning and teaching in higher education: Gulf perspectives 6(2). 
The percentage difference on eight of the item groups was $18 \%$ or less. Surprisingly, the difference is almost negligible on item 12 .

The statistical test of the four hypothesis presented in this paper are addressed next.

\section{Test of the Hypotheses}

The research data was copied into a statistical analysis program (SPSS). A t-test was performed to determine differences in the overall score based on gender.

Group Statistics

\begin{tabular}{|ll|l|l|l|l|}
\hline & Gender & N & Mean & $\begin{array}{l}\text { Std. } \\
\text { Deviation }\end{array}$ & $\begin{array}{l}\text { Std. Error } \\
\text { Mean }\end{array}$ \\
\hline Scoring & Male & 119 & 44.95 & 11.450 & 1.050 \\
& Female & 242 & 45.83 & 12.390 & .796 \\
\hline
\end{tabular}

Comparing the means of the males (44.95) with those of the females (45.83), the means are very close with a slight advantage for the females. This was the same result obtained by Ennis (1965). However it can be concluded that there is no significant difference in the results on this test between the females and the males. Therefore Hypothesis 1 , stating that there would not be a significant difference has proven to be true.

To test Hypotheses 2,3 and 4, a bivariate correlation was performed. This was done after screening the data for outliers and developing a scatter plot to determine evidence of a linear relationship. The bivariate correlations between the students score on the Cornell Conditional-Reasoning Test, Form X and the dependent variables - age, GPA and number of credit hours completed- were conducted. The results are presented in Table 4.

Table 4: Correlation Results.

\begin{tabular}{|ll|l|l|l|l|}
\hline & & & & $\begin{array}{l}\text { Number } \\
\text { of Credit } \\
\text { Hours }\end{array}$ \\
\hline Scoring & Scoring & Age & GPA & Pearson \\
& $\begin{array}{l}\text { Correlation } \\
\text { Sig. (2-tailed) }\end{array}$ & 1 & $-.117\left(^{*}\right)$ & -.007 & -.025 \\
& $\mathrm{~N}$ & .048 & .890 & .645 \\
& 361 & 285 & 355 & 347 \\
\hline
\end{tabular}

* Correlation is significant at the 0.05 level (2-tailed).

There is a significant difference in scores due to age; however, that difference is a negative correlation (.117). Hypothesis 2 stated that there would be a significant difference because of age but that the difference in the results would favour the older students. That is not the case in this study. Surprisingly, younger students (ages 18-21), whom it was assumed had less English language exposure and less life experience did better on this test than did older students (ages 22-25). Something, be it better language training or training in critical thinking skills has entered into the educational system in the UAE in the 
past few years and has equipped younger students with more deductive reasoning ability than older students.

To probe deeper, an analysis of variances (anova) was conducted to compare the mean scores of students at each age group. The result is presented in Table 5.

Table 5: Comparison of means based on age.

\begin{tabular}{|l|l|l|l|}
\hline Your Current Age & Mean & N & $\begin{array}{l}\text { Std. } \\
\text { Deviation }\end{array}$ \\
\hline Category 1- age18 & 47.94 & 50 & 12.458 \\
Category 2-age 19 & 47.85 & 30 & 11.840 \\
Category 3-age 20 & 45.10 & 61 & 13.455 \\
Category 4-age 21 & 44.11 & 88 & 11.587 \\
Category 5-age 22 & 43.38 & 39 & 13.240 \\
Category 6-age 23 & 47.55 & 10 & 9.825 \\
Category 7-age 24 & 43.88 & 4 & 14.144 \\
Category 8-age 25 or older & 40.00 & 3 & 16.726 \\
Total & 45.36 & 285 & 12.427 \\
\hline
\end{tabular}

The age group with the highest mean was the eighteen year old students followed closely by the nineteen year olds. Strangely, the next highest mean according to age are the 23 year old students. The conclusion for Hypothesis 2 is that there is a significant negative correlation in test scores due to age.

Concerning the final two hypotheses, it was stated that there would be a significant difference on the test due to both the GPA scores achieved by students and the number of credit hours completed. However, as Table 6 and Table 7 indicate, there was no significant differences in the mean scores on this test based on either a student's GPA or the credit hours a student has completed.

Table 6: t-test of students with GPA greater than 3 and less than 3.

\begin{tabular}{|l|l|l|l|l|l|}
\hline \multicolumn{2}{|c|}{$\begin{array}{l}\text { Your Current GPA } \\
\text { is }\end{array}$} & $\mathrm{N}$ & Mean & $\begin{array}{l}\text { Std. } \\
\text { Deviation }\end{array}$ & $\begin{array}{l}\text { Std. Error } \\
\text { Mean }\end{array}$ \\
\hline Scoring & $>=3$ & 193 & 45.20 & 12.236 & .881 \\
& $<3$ & 162 & 45.89 & 11.796 & .927 \\
\hline
\end{tabular}

Table 7: t-test of students with 68 credit hours or more and students with less than 68.

\begin{tabular}{|ll|l|l|l|l|}
\hline \multicolumn{2}{|c|}{$\begin{array}{l}\text { Number of Credit } \\
\text { Hours including this } \\
\text { semester }\end{array}$} & $\mathrm{N}$ & Mean & $\begin{array}{l}\text { Std. } \\
\text { Deviation }\end{array}$ & $\begin{array}{l}\text { Std. Error } \\
\text { Mean }\end{array}$ \\
\hline Scoring & $>=69$ & 197 & 45.39 & 11.556 & .823 \\
& $<69$ & 150 & 45.76 & 12.941 & 1.057 \\
\hline
\end{tabular}

Therefore, Hypotheses 3 and 4 have been shown to be not conclusive. 


\section{Conclusion}

The students at UAEU encountered the same difficulties with logically invalid statement as did the students in the USA and Jamaican study. Principles two, three, seven and twelve are all invalid statements and the scores were very low with only a small percentage of students demonstrating mastery of those principles. The correct answer to those four principles is "maybe"; such statements require the student to be very discerning when considering the validity of the question. UAEU students demonstrated reasonable mastery of principles one (44.5\%), five (41\%), eight $(57.34 \%)$ and nine (56.74\%); these four principles are valid arguments requiring for the most part an answer in the affirmative. Strangely, the results are low on mastery of principle six even though it is a valid statement answered in the affirmative; perhaps, students are confused with the double negative in the consequent part of the statement. This pattern of results follow very closely the same pattern evident in both United States and West Indies research projects as outlined in Table 2.

Consistent with other studies, there was no significant difference in performance on this test between female and male students. In this study, there were also no significant differences between students with a GPA of three or more and students with a GPA of less than three There was no significant difference in performance between students with more than sixty-eight credit hours and those with less. This result is contrary to the results achieved on the Watson- Glaser test where MBA and medical students achieved the highest scores (Norris 1985).

However, there was a significant difference in performance on the Cornell Conditional-Reasoning Test Form $X$, between students eighteen to twenty-two years old and older students. This was a negative correlation indicating that younger students performed better.

The USA students did better than the Jamaican and UAEU students. The percentage differences in the overall mean score on this test between the UAEU students and the USA students is 23\% ((56.645.9)/45.9) and with the Jamaican students it was $3 \%((47.3-45.9) / 45.9)$.

The pilot study indicated that students had difficulty with the terminology in four of the seventy-two questions - questions $43,52,62$ and 66 . If the results on these four questions were removed from the marking scheme and a revised marking scheme of $\mathrm{R}-\mathrm{W} / 2+31$ was used, the overall mean for the UAEU students would be 48.3 . A mean score slightly greater than the Jamaican score ( $2 \%$ difference) and with a $17 \%$ instead of a $23 \%$ difference compared with the USA results.

The conclusion of this study would be that the Cornell Conditional-Reasoning Test, Form X, as originally developed in 1964 can be considered an effective tool for measuring the deductive reasoning abilities of students in the UAE. This conclusion is based on the fact that the UAE students achieved a score very close to the results achieved in Jamaica (45.9 versus 47.3 ) and within a 10 point mean score with of students in the United States (56.6) - a third of whom received training in deductive reasoning.

Implications of this study for further research would be that because the Cornell Conditional-Reasoning Test Form X can be easily adapted it can then be used to assess the deductive reasoning abilities of UAE students. The test can be adapted in two ways: 1) leave the test in English but use terms that are familiar to students living in the Middle East and 2) translate the test into Arabic using the concrete familiar terms developed in the first scenario.

Researching the deductive reasoning abilities of UAE students provides a unique opportunity. The cultural background of the students is very homogeneous unlike that of students in North America. Adapting the test to use terms familiar to UAE students would provide more insight into Norris's (1985) assertion that critical thinking ability is sensitive to context and McPeck's (1981) finding that people do

McLellan, J. (2009). Establishing a benchmark for the deductive reasoning abilities of United Arab Emirates University Business students. Learning and teaching in higher education: Gulf perspectives 6(2). 
better at deductive reasoning when the contexts relate to their experience. Also, translating the test into Arabic would provide indications of the degree that the role of language plays in measuring deductive reasoning abilities.

A future research project would be to randomly test female college and university students in the UAEhaving one-third taking the test without any modifications ( similar to the current project); one- third taking the test in English but with terms familiar to an Arabic student and one-third taking the test completely in Arabic using terms familiar to an Arabic student. The test in Arabic can then be used to test the deductive reasoning abilities of UAE students in grades five to twelve and to measure improvement in deductive reasoning abilities over time.

\section{References}

Bradshaw, K., Tennant, L. and Lydiatt, S. (2004). "Special Education in the United Arab Emirates: Anxieties, Attitudes and Aspirations." International Journal of Special education 19(1): 29-55.

Brandon, E. P. (1989). Gender and Competence in Deductive Logic. Department of Educational Studies, UWI, Mona Jamaica.

Brandon, E. P. (1997). Jamaican teachers and deductive logic. Caribbean Journal of Education 19: 113130.

Broadbear, James T. (2003). Essential Elements of lessons designed to promote Critical Thinking. The Journal of Scholarship of Teaching and Learning, 3(3). Illinois State University.

Cheng, P. W. \& Holyoak, K.J. (1985). Pragmatic reasoning schemas. Cognitive Psychology, 17.

Cheng, P. W., Holyoak, K.J., Nisbett, R.E.\& Oliver, L.M. (1986). Pragmatic versus syntactic approaches to training deductive reasoning. Cognitive Psychology 18.

Ennis, R.H. (1999). An annotated list of critical thinking tests. Accessed 3 June 2009 at

http://www.criticalthinking.net/CTTestList1199.html

Ennis, R. H., \& Paulus, D.H. (1965). Critical Thinking readiness in grades 1-12) .Phase 1, deductive reasoning in adolescence). Ithaca, NY: Cornell University.

Ennis, R. H., Gardiner, W.L., Guzzetta, J., Morrow, R, Paulus D. and Ringel, L (1964). The Cornell Conditional Reasoning Test, Form X. Cornell Critical Thinking Project. Ithaca, NY: Cornell University.

Ennis, R.H. and Weir, E.(1985) The Ennis and Weir Critical Thinking Essay Test. Pacific Grove, CA: Midwest Publications.

Facione, P.A. (1991). Using the California Critical Thinking Skills test in Research, Evaluation and Assessment. Millbrae, CA: California Academic Press.

Johnson-Laird, P.N. \& Byrne R.M. (1991) Deduction. Hillsdale,NJ

Johnson-Laird, P.N. (1983). Mental Models: Towards a cognitive science of language, inference and consciousness. Cambridge University Press.

McPeck, J. (1981). Critical Thinking and Education. Oxford University Press.

Nolan, C., \& Brandon, E.P. (1984). Conditional Reasoning in Jamaica. Conference on Thinking, Harvard, Boston, Mass.

McLellan, J. (2009). Establishing a benchmark for the deductive reasoning abilities of United Arab Emirates University Business students. Learning and teaching in higher education: Gulf perspectives 6(2). 
Norris, S.P. (1985). Synthesis of Research on Critical Thinking. Educational Theory.

Siege, G. (2000). Skills needed for entry-level management accounting positions. Strategic Finance, 81(10).

\section{Author}

Dr. John McLellan currently teaches Management Accounting at Abu Dhabi University. He has an extensive background in management consulting in Canada as well as in the UAE. He holds an MBA and a doctorate, and his research interests are in the area of accounting education. He became interested in improving the deductive reasoning abilities of UAE students four years ago when he realized that his students were relying on memorization when attempting to analyze and solve problems within a business context. 


\section{Appendix}

Thank you for taking the time to complete this survey for the College of Business and Economics. This is called the Cornell University Conditional-Reasoning test.

This is a test to see how well you do a particular kind of thinking. You will see that you already do some of this kind of thinking. Do not guess wildly. You should work as quickly as you can, but do not rush. This is not a speed test.

There are 72 questions numbered from 7-78. The test generally takes between $30-50$ minutes to complete.

You will be given one or more sentences with which to think. You will then be given another sentence, about which you must decide, using only what you were told. There are three possible answers:

1. Yes - it must be true

2. No - it can't be true

3. Maybe - it may be true or it may not be true. You were not told enough to be certain whether it is "Yes" or "No".

In answering each question, use only what you were told in that question. Even though you may know a thing is false - for that question you must suppose that it is true.

Sample Questions:

1. Suppose you know that

Bill is next to Sam.

Then would this be true?

Sam is next to Bill. (The answer is yes - it must be true.)

\section{Suppose you know that:}

The sparrow is over the hawk.

Then would this be true?

The hawk is over the sparrow. (NO - it can't be true.)

\section{Suppose you know that}

Jane is standing near Betsy.

Then would this be true?

Betsy is standing near Jane. (Maybe- Even though Jane is standing near Betsy, Betsy could be sitting. You were not told enough to be certain.)

\section{Suppose you know that \\ California is near New York.}

Then would this be true?

New York is near California. (Yes - even though you know the first statement is obviously false you 
must for this question accept the statement as being true. If California were near New York, then New York would be near California. It would have to be true.) 